\title{
Trefoil Factor 3 Deficiency Affects Liver Lipid Metabolism
}

\author{
Maro Bujak ${ }^{a}$ Ivana Tartaro Bujak ${ }^{b}$ Sandra Sobočanec ${ }^{c} \quad$ Martina Mihalj $^{d}$ \\ Sanja Novak ${ }^{d}$ Anita Ćosićd Maja Tolušić Levake Vjekoslav Kopačin ${ }^{f}$ \\ Branka Mihaljevićc $^{b} \quad$ Tihomir Balog $^{c}$ Ines Drenjančevićd ${ }^{d}$ Mirela Baus Lončar ${ }^{g}$ \\ aLaboratory for Biotechnology in Aquaculture, Division of Materials Chemistry, Ruđer Bošković Institute \\ (IRB), Zagreb, 'badiation Chemistry and Dosimetry Laboratory, Division of Materials Chemistry, IRB, \\ Zagreb, 'Laboratory for Reactive Radicals (LARRA), Division of Molecular Medicine, IRB, Zagreb, \\ dDepartment of Physiology and Immunology, Faculty of Medicine Osijek, University of Osijek,

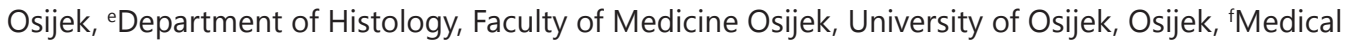 \\ Biochemistry Laboratory - Kopačin, Osijek, 'Laboratory for Neurodegenerative Disease Research, \\ Division of Molecular Medicine, IRB, Zagreb, Croatia
}

\section{Key Words}

Tff3 deficient mice $•$ Metabolism $•$ Fatty acids profile $•$ Oxidative stress

\begin{abstract}
Background/Aims: Tff3 protein plays a well recognized role in the protection of gastrointestinal mucosa. The role of Tff3 in the metabolism is a new aspect of its function. Tff3 is one of the most affected liver genes in early diabetes and fatty liver rodent models. The aim of this study was to investigate the effect of Tff3 deficiency on lipid and carbohydrate metabolism and on markers of oxidative stress that accompanies metabolic deregulation. Methods: Specific markers of health status were determined in sera of Tff3 deficient mice, including glucose level, functional glucose and insulin tolerance. Composition of fatty acids (FAs) was determined in liver and blood serum by using gas chromatography. Oxidative stress parameters were determined: lipid peroxidation level via determination of lipid hydroperoxide and thiobarbituric acid reactive substances (TBARS), antioxidative capacity (FRAP) and specific antioxidative enzyme activity. The expression of several genes and proteins related to the metabolism of lipids, carbohydrates and oxidative stress (CAT, GPx1, SOD2, PPAR $\alpha$, PPAR $\gamma$, PPAR $\delta, ~ H N F 4 \alpha$ and SIRT1) was determined. Results: Tff3 deficient mice showed better glucose utilization in the glucose and insulin test. Liver lipid metabolism is affected and increased formation of small lipid vesicles is noticed. Formation of lipid droplets is not accompanied by increased liver oxidative stress, although expression/activity of monitored enzymes is deregulated when compared with wild type mice. Tff3 deficient mice exhibit reduced expression of metabolism relevant SIRT1 and PPAR $\gamma$ genes. Conclusion: Tff3 deficiency affects the profile and accumulation of FAs in the liver, with no obvious oxidative stress increase, although expression/activity of monitored enzymes is changed as well as the level of SIRT1 and PPAR $\gamma$ protein. Considering the strong
\end{abstract}

M. Bujak and I. T. Bujak contributed equally to this work.

Mirela Baus Lončar and Ines Drenjančević
Laboratory for Neurodegenerative Disease Research, Division of Molecular Medicine, Department of Physiology and Immunology, Faculty of Medicine Osijek (Croatia) Tel. +385 1457 1327, +38591 2241406, E-Mail mbaus@irb.hr 


\section{Cellular Physiology Cell Physiol Biochem 2018;47:827-841 \\ \begin{tabular}{l|l} 
and Biochemistry Published online: Vay 28, 2018 & $\begin{array}{l}\text { (c) 2018 The Author(s). Published by S. Karger AG, Basel } \\
\text { www.karger.com/cpb }\end{array}$ \\
\hline
\end{tabular} \\ Bujak et al.: Tff3 $\%$ Genotype Affects Liver Lipid}

downregulation of liver Tff3 in diabetic/obese mice, presence in circulation and regulation by food/insulin, Tff3 is an interesting novel candidate in metabolism relevant conditions.

(C) 2018 The Author(s)

Published by S. Karger AG, Basel

\section{Introduction}

Trefoil factor family proteins (Tff1, Tff2, Tff3) are small and compact peptides containing one (Tff1, Tff3) or two (Tff2) so called trefoil domains [1]. They are highly expressed in the gastrointestinal tract as secretory proteins involved in the maintenance of epithelial barrier integrity during the process of restitution upon mucosal injury [2]. Namely, mice with targeted disruption of intestinal trefoil factor (Tff3) exhibited impaired mucosal healing and died from extensive colitis after oral administration of dextran sulfate sodium, an agent that causes mild epithelial injury in wild type mice. Tff3 is present in human serum at a high concentration (200 pmol/L) but the origin of circulating Tff3 is unknown [3]. However, a body of evidence demonstrates that Tff proteins (Tffs) are widely distributed [4] and may play other important roles also in the immunological defense [5]. In addition, Tffs have been increasingly recognized as novel participants in complex metabolic interactions [6].

Tff3 protein expression in normal human liver is localized mainly to the large bile ducts and mucinous peribiliary glands [6]. The role of Tff3 in intestinal inflammatory diseases [7] and regulation by multiple regulatory pathways [5] is well recognized. Potential role of Tff3 gene in the metabolism relevant condition called diabesity (combination of diabetes and obesity) was revealed for the first time by quantitative trait locus (QTL) analysis of the mouse diabesity model, Tally Ho mouse strain [8]. When comparing mRNA transcriptome in relevant tissues (adipose tissue, pancreas, and liver), Tff3 mRNA was found as being most affected in the liver, where it was reduced by almost 600 times in the early diabetic state of these mice [8]. In another study, serum level of Tff3 was increased by insulin, glucose and food intake in T1D patients as well as in healthy subjects [9]. In addition, Tff3 overexpression in vivo improved glucose tolerance in a dietary induced obesity mouse model without affecting the body weight, fasting insulin, triglyceride, cholesterol and leptin levels [10]. Recently, Xue et al. [11] reported that overexpression of Tff3 in primary mouse hepatocytes inhibited the expression of gluconeogenic genes and improved glucose tolerance and insulin sensitivity. They also showed that hepatic Tff3 expression levels were decreased in obese mice and in the high fat diet induced mouse model. Moreover, hepatic Tff3 expression levels were decreased in obese and high fat diet induced mice compared to control mice [12].

Blood glucose homeostasis is regulated by the liver: in fasting time, the liver synthesizes glucose through both glycogenolysis and gluconeogenesis, or in the fed state, hepatocytes store excess glucose as glycogen [13]. In the fed state, hepatocytes use glycolytic products in the process of de novo lipogenesis to synthesize fatty acids. Long chain fatty acids in hepatocytes are incorporated into triacylglycerol, phospholipids, and/or cholesterol esters. These complex lipids are stored in lipid droplets and membrane structures, or secreted into the circulation as very low density lipoprotein particles [14]. Deregulated liver metabolism promotes insulin resistance, diabetes and nonalcoholic fatty liver diseases (NAFLD) [15]. Recently it was demonstrated that liver triglyceride accumulation does not cause cellular injury per se in the liver. Free fatty acids or their metabolites are primarily responsible for liver injury via increased oxidative stress (OS) [16]. Changes in lipid metabolism, in particular the increase of saturated fatty acids, is associated with increased endoplasmatic reticulum (ER) stress, oxidative stress and liver injury in the course of development of fatty liver disease [17]. Oxidative stress, as an overall state of substantial imbalance between reactions of free radicals, as oxidizing species, and antioxidants within the cells and tissues, leads to oxidative damage of proteins, lipids, and DNA. Accumulation of lipid (hydro)peroxides and their degradation products, due to lipid peroxidation processes and stimulating glutathione depletion, leads to oxidative damage of different organelles in liver tissue and participates in fatty liver disease development [18]. Increased Tff3 gene expression is noticed in the late phase of response of human tumor cells to oxidative stress [19]. 
SIRT1 has attracted a lot of interest as it plays a key role in metabolic regulation, adaptation and oxidative stress. It acts as a nuclear metabolic sensor and deacetylates a wide range of targets, leading to epigenetic modifications of histones and modulation of transcription factors or metabolic enzymes [20]. It has been shown that downregulation of sirtuins has an important role in the pathophysiology of fatty liver disease in humans and in animal models [21]. Besides SIRT1, peroxisome proliferator-activated receptors (PPARs) also play an important role in cell metabolism. They are ligand inducible transcription factors (nuclear receptors) that modulate the expression of genes involved in adipogenesis, lipid and glucose metabolism, energy homeostasis and inflammation [22]. In mammals, there are three PPARs: PPAR $\alpha$, PPAR $\beta / \delta$ and PPAR $\gamma$. Among them, PPAR $\gamma$ as a nuclear receptor central to glucose and lipid homeostasis appears to play a major role in promoting development of fatty liver [23].

The aim of this study was to investigate the effect of Tff3 deficiency on lipid and carbohydrate metabolism by using Tff3 knockout mouse model (accepted nomenclature for: genotype: Tff3 -/-; protein: Tff3 deficiency). We have determined specific markers of health status in the sera of Tff3 deficient mice, as well as the glucose level and response to glucose and insulin overload. Oxidative stress level was assessed by determination of lipid hydroperoxides and thiobarbituric acid-reactive substances (TBARS), antioxidative capacity (FRAP) and antioxidative enzyme activity. Given that the liver is one of the major metabolic organs involved in lipid metabolism, we have determined the impact of Tff3 deficiency on the level of hepatic neutral lipid accumulation and FAs profile, which was correlated with FAs profile in blood serum. Furthermore, the expression of several genes related to metabolism of lipids, carbohydrates and oxidative stress (CAT, GPx1, SOD2, PPAR $\alpha$, PPAR $\gamma$, PPAR $\delta$, HNF $4 \alpha$ and SIRT1) was assessed. The protein level of relevant genes was determined to provide possible mechanistic explanation.

\section{Materials and Methods}

All used chemicals were of analytical reagent grade purity: KOH (Merck, Germany), KCl, EDTA, NADPH, sodium azide, $\mathrm{H}_{2} \mathrm{O}_{2}$, MDA, TBA, TPTZ (2,4,6-tris(2-pyridyl)-s-triazine), Trolox, $\mathrm{MgCl}_{2}$ (Sigma-Aldrich, Germany). All solvents (Merck, Germany) were used without further purification.

\section{Animals and sample collection}

All animal housing conditions and research protocols were approved by the National Local Ethical Committee. Trefoil factor 3 protein-deficient mice were a gift from Prof. W. Hoffmann (previously described [2] (nomenclature: genotype: Tff3 -/-; protein: Tff3), as well as the appropriate wild type (WT) mice of mixed background (C57Bl6/ Sv/129 mice). They were kept at the Animal Facility of the Faculty of Medicine Osijek (Croatia). Care and use of the animals and the experimental protocol were reviewed and approved by the Institutional Ethical Committee. Mice were kept under standard conditions and fed (ad libitum) with standard chow diet until 12 weeks old, when they are deemed to represent physiologically matured mice. The mice were fasted for 6 hours before being sacrificed. The animals (males, min. 7 per group) were sacrificed, and blood was collected for further general blood chemistry analysis comprising the following routine blood biochemistry analysis: Fe, high-density lipoprotein (HDL), glucose, cholesterol, aspartate transaminase (AST), alanine transaminase (ALT), urea, creatinine, bilirubin, triglycerides (TG), alkaline phosphatase (AP), total proteins (TP), Na, K, amylase, lactate dehydrogenase (LDH), creatine kinase (CK). Liver tissue samples were snap-frozen in liquid nitrogen or fixed in $10 \%$ formalin and processed for regular histological analysis (HE, PAS) and lipid staining (Oil Red). Tissue sections were examined by experienced pathologist blinded to genetic origin of the mice.

Glucose and insulin tolerance test

Tff3 -/- and WT mice were used to perform glucose or insulin tolerance test. Mice (n=7) were fasted for 6 hours before intraperitoneal injection of glucose ( $2 \mathrm{~g} / \mathrm{kg}$ body mass; Merck, Germany) or insulin $(0.75$ IU/g body weight; Levemir, Novo Nordisk, UK). Blood glucose concentration measurements were taken 


\section{Cellular Physiology Cell Physiol Biochem 2018;47:827-841 \begin{tabular}{l|l|} 
and Biochemistry Published 10.1159/000490039 & $\begin{array}{l}\text { C } 2018 \text { The Author(s). Published by S. Karger AG, Basel } \\
\text { www.karger.com/cpb }\end{array}$ \\
\hline
\end{tabular}}

Bujak et al.: Tff3 $\%$ Genotype Affects Liver Lipid

from the tail vessels of the mice, at the following points in time: 0 (just before glucose injection), 15, 30, 60, 90 and 120 min after glucose or insulin injection.

\section{Analysis of fatty acids}

Liver tissue $(0.2 \mathrm{~g}$ ) was cut into small pieces and homogenized in PBS. Total lipids were extracted from serum $(50 \mu \mathrm{l})$ and from tissue homogenates according to Bligh and Dyer [24]. The lipid extract was treated with $0.5 \mathrm{M} \mathrm{KOH} / \mathrm{MeOH}$ (Merck, Germany) for $20 \mathrm{~min}$ at room temperature [25], and the corresponding fatty acid methyl esters (FAMEs) were formed, extracted with n-hexane (Merck, Germany), and analyzed by gas chromatography (GC). An internal standard (C19:0, Sigma Aldrich, Germany; $8.13 \mu$ g) was added to all samples. The FAME samples from liver and serum were diluted with $250 \mu \mathrm{l}$ and $100 \mu \mathrm{l}$ of n-hexane, respectively. $1 \mu \mathrm{l}$ was injected to GC in a split mode (20:1). GC analyses of FAME were performed by using Varian 450-GC equipped with a flame ionization detector. A Stabilwax column (crossbond carbowax polyethylene glycol, $60 \mathrm{~m} \times 0.25 \mathrm{~mm}$; Restek) was used as a stationary phase at a programmed temperature, with helium (Messer, Germany) as the carrier gas. The heating was carried out at a temperature of $150{ }^{\circ} \mathrm{C}$ for $1 \mathrm{~min}$, followed by an increase of $5{ }^{\circ} \mathrm{C} / \mathrm{min}$ up to $250^{\circ} \mathrm{C}$. The methyl esters were identified by comparison with retention times of standard commercially available mixtures (Marine oil FAME mix, Restek, USA). Individual fatty acids were determined in the liver $(n=7)$ and serum $(n=7)$ of wild type and Tff3 deficient mice and expressed as relative percentages of FAME obtained from total lipid extract. The relative amount of each fatty acid (percentage of FAME) was quantified by integrating the area under the peak and dividing the results by the total area for all fatty acids.

\section{Quantitative real-time PCR analysis}

Total RNA was extracted from individual mouse livers by RNeasy spin columns (Qiagen, MD, USA), followed by DNase treatment in accordance with the manufacturer's protocol. RNA was reverse transcribed by using the High Capacity cDNA Reverse Transcription Kit (Applied Biosystems, CA, USA), according to the manufacturer's instructions, by using $1 \mu \mathrm{g}$ of total RNA. qPCR analysis was carried out on an ABI 7300 sequence detection system by using predesigned TaqMan Gene Expression Assays, Thermo Fisher scientific (MA, USA): Beta-actin (Mm00607939_s1) as reference gene; Superoxide dismutase 2 (Mm01313000_ $\mathrm{m} 1)$, Catalase (Mm00437992_m1), PPAR $\alpha$ (Mm00627559_m1), PPAR $\beta / \delta$ (Mm01305434_m1), PPAR $\gamma$ (Mm00440940_m1), HNF4 $\alpha$ (Mm00433964_m1), GPx1 (Mn00656767_g1) and SIRT1 (Mm00490758_ $\mathrm{m} 1)$. The data were presented as whisker-box plots based on the permutated expression data. Expression variation is visualized for each gene in a whisker-box plot to provide additional information about the skew of the data distributions that would not be available simply by plotting the sample mean [26].

\section{Western blot analysis}

Liver samples were homogenized (Potter-Elvehjem homogenizer; $1300 \times$ g) with RIPA buffer (Thermo Fisher scientific MA, USA) supplemented with proteinase inhibitors (10\% w/v) (Roche, Switzerland), sonicated ( $3 \times 30 \mathrm{sec}$ ) and centrifuged at $16000 \mathrm{~g} / 20 \mathrm{~min}$ in a refrigerated centrifuge. Supernatant was collected and total cellular proteins $(100 \mu \mathrm{g}$ per lane) were resolved by denaturing SDS-PAGE and transferred on a PVDF or nitrocellulose membrane (Bio-Rad, CA, USA). Membranes were blocked in 5\% nonfat dry milk (Bio Rad, CA, USA) in TN buffer (50 mM TRIS; Merck, Germany; 150 mM NaCl; Merck, Germany pH=7.4) and incubated overnight $\left(4{ }^{\circ} \mathrm{C}\right)$ with appropriate primary polyclonal antibody SIRT1, iNOS and PPAR $\gamma$ (Santa Cruz Biotechnology, TE, USA; diluted 1:200), PMP70 (Thermo Fisher scientific, MA, USA; diluted 1:500). Antibodies against SOD2, CAT, GPx1 (Abcam, UK; diluted 1:200) were incubated 3 hours at room temperature. Donkey anti-rabbit IgG, horseradish peroxidase-conjugated secondary antibody (Amersham Biosciences, UK) was incubated for 3 hours at room temperature. Equality of loading was confirmed by using AmidoBlack (Sigma Aldrich, USA), which was also used for normalization of the bands [27]. The chemiluminescence signals were detected and analyzed with the Alliance 4.7 Imaging System (UVITEC, Cambridge, UK).

\section{Oxidative stress parameters}

Antioxidant enzyme activities assay

Liver samples were weighed and crushed with liquid nitrogen and homogenized in an adequate solution with Ultra turrax T10 homogenizer while kept on ice. For SOD and GPx activity assay, liver tissue was homogenized (1:10, w/v) in $50 \mathrm{mM}$ phosphate buffer $(\mathrm{pH}=7.8)$ and for CAT activity assay $(1: 10, \mathrm{w} / \mathrm{v})$ in $100 \mathrm{mM}$ phosphate buffer ( $\mathrm{pH}$ 7.0) containing 1 mM EDTA. Total SOD activity was determined by inhibition 


\section{Cellular Physiology Cell Physiol Biochem 2018;47:827-841 \\ \begin{tabular}{ll|l} 
DOI: 10.1159/000490039 & O 2018 The Author(s). Published by S. Karger AG, Basel \\
www.karger.com/cpb
\end{tabular} \\ Bujak et al.: Tff3 $\%$ Genotype Affects Liver Lipid}

of reduction of cytochrome C $(0.05 \mathrm{mM})$ in PBS buffer saline with $0.1 \mathrm{mM}$ EDTA in the system of the xanthine $(1 \mathrm{mM}) / x a n t h i n e ~ o x i d a s e(50 \mathrm{U})$. GPx activity was assessed indirectly at absorbance wavelength of $340 \mathrm{~nm}$ during 5 minutes of NADPH oxidation to NADP+. The assay mixture consisted of $50 \mathrm{mM}$ phosphate buffer with $0.4 \mathrm{mM}$ EDTA and $1 \mathrm{mM}$ sodiumazide ( $\mathrm{pH}=7.0$ ), $0.12 \mathrm{mM} \mathrm{NADPH}, 3.2$ units of GR, $1 \mathrm{mM}$ glutathione, and $0.0007 \%(\mathrm{w} / \mathrm{w}) \mathrm{H}_{2} \mathrm{O}_{2}$. One unit of GPx activity catalyzes the oxidation by $\mathrm{H}_{2} \mathrm{O}_{2}$ of $1.0 \mu \mathrm{mol}$ of reduced glutathione to oxidized glutathione per minute at $\mathrm{pH}=7.0$ and $25^{\circ} \mathrm{C}$. GPx activity was calculated by using molar extinction coefficient for NADPH disappearance $\left(\varepsilon=6220 \mathrm{dm}^{3} \mathrm{~mol}^{-1} \mathrm{~cm}^{-1}\right)$ [28]. CAT activity was measured using $\mathrm{H}_{2} \mathrm{O}_{2}(0.036 \%)$ as a substrate in the reaction mixture with $50 \mathrm{mmol} / \mathrm{L}$ phosphate buffer $\mathrm{pH}$ (7.0). Absorbance was measured at $240 \mathrm{~nm}$ during 2 minutes, every 10 seconds after adding the sample. One unit of activity corresponds to the loss of $1 \mu \mathrm{mol}$ of $\mathrm{H}_{2} \mathrm{O}_{2}$ per minute. CAT activity was calculated by using molar extinction coefficient $\left(\varepsilon=0.04 \mathrm{dm}^{3} \mathrm{~mol}^{-1} \mathrm{~cm}^{-1}\right)$ [28]. Activity of enzymes was expressed as $\mathrm{U} / \mathrm{mg}$ protein $(\mathrm{U} / \mathrm{mg} \mathrm{P})$ and protein concentration was determined by Bradford protein assay. All measurements were done at Lambda 25 UV-Vis spectrophotometer equipped with UV WinLab 6.0 software package (PerkinElmer For the Better, Waltham, Massachusetts, USA) [29].

\section{TBARS and FRAP}

Liver samples were weighed and crushed with liquid nitrogen and homogenized in ice-cold $1.15 \%$ $\mathrm{KCl}$ solution (1:10, w/v) by using Ultra turrax T10 homogenizer while kept on ice. Malondialdehyde (MDA), the final degradative product of lipid hydroperoxides formed in lipid peroxidation process, reacts with thiobarbituric acid and the colored products were used as indicators of oxidative stress [30]. The absorbance of the sample was measured at 572 and $532 \mathrm{~nm}$ against the reagent and results were expressed as $\mu \mathrm{mol}$ MDA by using a calibration curve obtained with MDA.

Antioxidant capacity was assessed by using FRAP. Presence of antioxidants caused blue discoloration of solution due to reduction of the ( $\mathrm{Fe}^{3+} \mathrm{TPTZ}$ ) complex to ( $\left.\mathrm{Fe}^{2+} \mathrm{TPTZ}\right)$ complex [31]. Trolox was used as standard (Sigma). The absorbance of the sample was measured at $593 \mathrm{~nm}$ and results were expressed as mM Trolox (mM TE). Both-spectrophotometric methods were carried out on Nanophotometer P300 UV/ VIS, IMPLEN.

\section{Lipid hydroperoxide analysis in isolated lipid extracts}

Liver samples were snap-frozen and stored at $-80^{\circ} \mathrm{C}$ until analysis. Lipids were extracted according to the modified method of Kramer et al. [32]. Briefly, $0.2 \mathrm{~g}$ of liver tissue was cut and homogenized in PBS. Lipid extraction started by adding $5 \mathrm{ml}$ of $\mathrm{CHCl}_{3}$ to the homogenate, followed by vigorous shaking. The solution was washed with $1.5 \mathrm{ml}$ of $0.034 \% \mathrm{MgCl}_{2}$, centrifuged ( $2 \mathrm{~min}$, at $3000 \times \mathrm{g}$ ) and the aqueous layer was drawn off by aspiration using a Pasteur pipette. The washing procedure was repeated with $2.5 \mathrm{ml}$ of $2 \mathrm{M} \mathrm{KCl} / \mathrm{MeOH}$ $(4: 1, \mathrm{v} / \mathrm{v})$ to eliminate all proteins and non-lipid contaminants. $\mathrm{CHCl}_{3}$ layer was finally washed with $\mathrm{CHCl}_{3} /$ $\mathrm{MeOH}(2: 1, v / v)$ and centrifuged for $5 \mathrm{~min}$ at $3000 \times \mathrm{g}$. The organic layer containing lipids was carefully transferred to a glass tube and solvent was removed on a rotary evaporator. After weighing, the lipids were stored at $-20^{\circ} \mathrm{C}$ until analysis of lipid hydroperoxides $(\mathrm{LOOH})$. Spectrophotometric ferric thiocyanate assay was used for determination of $\mathrm{LOOH}$ concentration. Samples were prepared according to the following procedure [33]. The analyzed samples were prepared by diluting with a deaerated mixture of $\mathrm{CH}_{2} \mathrm{Cl}_{2} / \mathrm{MeOH}$ $(2: 1, \mathrm{v} / \mathrm{v})$. The concentrations of LOOH were calculated by using the molar absorptivity of the complex $[\mathrm{FeNCS}]^{2+}$ formed per mol of LOOH, $58440 \mathrm{dm}^{3} \mathrm{~mol}^{-1} \mathrm{~cm}^{-1}$, at $500 \mathrm{~nm}$ [33].

\section{Statistical analysis}

The differences between WT and Tff3-/- mice were compared with Student $t$ test or with Two-way ANOVA and Bonferonni post-Hock test (GTT and ITT). For all tests, the significance level was set at $\mathrm{p} \leq 0.05$. Gene expression data were analyzed by REST 2009 expression analysis software [26].

\section{Results}

\section{Biochemistry}

Generally, Tff3 deficiency did not affect body weight so there was no significant difference between WT $(24,43 \pm 1.05)$ and Tff3 $-/-$ mice $(23.28 \pm 0.54)$ on a standard diet (mean value \pm 
SEM). Biochemical analysis of WT and Tff3 deficient mice sera (Table 1) showed no difference in kidney function (urea and creatinine), lipid metabolism (HDL, TG) or liver function (ALT, AST). Tff3 deficient mice had a significantly lower total protein level (reduced by $20 \%$ ) and serum amylase concentration (22\% reduction) compared with WT mice (Table 1$)$.

\section{Glucose and insulin tolerance test}

Blood glucose concentration was not changed in Tff3 deficient mice compared with WT mice (Table 1). Glucose tolerance test (Fig. 1A) showed that Tff deficient mice had a significantly lower level of glucose at 15 and $30 \mathrm{~min}$ upon its administration, while at other time intervals the glucose concentration was similar to glucose concentration in the blood of WT mice. Insulin tolerance test (Fig. 1B) showed that Tff3 deficient mice utilize glucose from the blood stream more effectively at 15 and 30 min upon insulin injection, compared with WT mice. Glucose concentrations were similar at other time points.

\section{Histomorphology of liver}

Histomorphology of the liver was not affected by Tff3 deficiency and the PAS staining showed no change in liver glycogen amount (data not presented). Oil Red staining of the liver (Fig. 2A, B) demonstrated that Tff3 deficient mice had an increased number of smaller lipid containing vesicles in the hepatocytes compared with WT mice on a standard diet.

\section{Liver and serum fatty acids profile}

Composition of fatty acids (FAs) was determined in liver and serum of WT and Tff3 deficient mice

(Table 2 and 3). The major fatty acids detectable were: palmitic acid (C16:0), stearic acid (C18:0), oleic acid (C18:1, $\omega-9)$, linoleic acid (LNA, 18:2, $\omega-6$ ), arachidonic acid (AA, C20:4, $\omega-6)$ and docosahexaenoic acid (DHA, 22:6, $\omega$-3). The monitored FAs were expressed as a relative percentage of FAME obtained from total lipid extract of the liver (Fig. 3A) and serum (Fig. 3B). Total lipid content showed no statistically relevant change, although it was slightly higher in Tff3 deficient mice $(9.2 \pm 1.8[\mathrm{mg} / \mathrm{mg}$ liver]) compared with WT mice $(7 \pm 0.8[\mathrm{mg} / \mathrm{mg}$ liver $]$ ).

Tff3 deficient mice had a significantly changed ratio of numerous $\mathrm{FA}$ in liver (Fig. 3A) and sera (Fig. 3B) compared with WT mice. The ratio of myristic acid (C14:0) was reduced (1.6-fold) in the liver of Tff3 -/- compared with WT mice, while stearic (C18:0) and arachidic (C20:0) FA ratio was increased (both 1.5fold) in the liver of Tff3-/- mice. Serum ratio of arachidic acid (C20:0) increased 1.8 -fold, as the only statistically affected

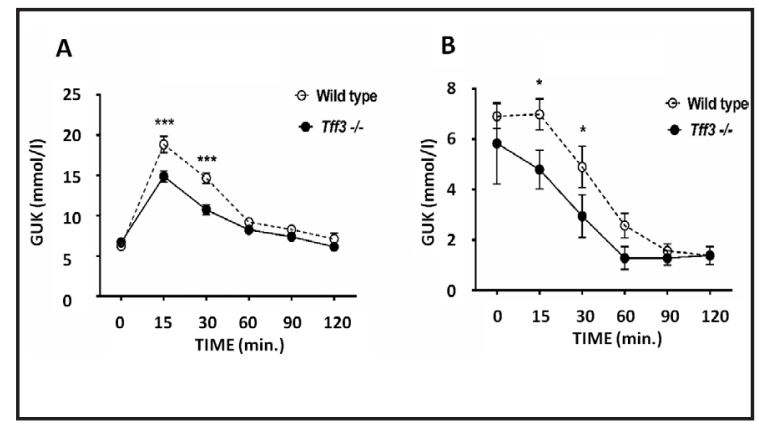

Fig. 1. Intraperitoneal glucose tolerance (GTT) and insulin tolerance (ITT) test in wild type and Tff3 -/mice. (A) Glucose tolerance test (2 $\mathrm{g} / \mathrm{kg}$ body mass) and (B) insulin tolerance test $(0.75 \mathrm{IU} / \mathrm{g}$ body weight) at time points $0,15,30,60,90$ and 120 min after glucose or insulin injection. Data are presented as mean values \pm SEM and compared with WT mice using Two-way ANOVA and Bonferonni post-Hock test. Statistically significant time points are marked as ${ }^{* *} \mathrm{p} \leq 0.01$ and ${ }^{* * *}$ $\mathrm{p} \leq 0.001$. 
saturated FA in Tff3 -/- mice. The level of saturated FA was slightly but statistically significantly increased (1.1fold) in the liver of Tff3 -/mice, while the sera content was unaffected.

Monounsaturated fatty acids (MUFAs) were significantly reduced in the liver of Tff3 -/- mice compared with their WT controls. Palmitoleic acid (C16:1) was reduced 2.6fold, oleic acid (C18:1) was reduced 1.8-fold, vaccenic acid (C18.1) was reduced 1.7-fold, and eicosenoic acid (C20:1) was reduced 1.3fold. Significantly changed MUFAs in sera of Tff3 deficient mice compared with WT were: vaccenic acid (C18:1), with 1.5-fold reduction, and eicosenoic acid (C20:1), with an almost 2-fold increased level. Altogether, levels of MUFAs were statistically decreased 1.7-fold in the liver of Tff3 -/mice, while the proportion in sera was not affected by Tff3 deficiency.

At the same time, polyunsaturated fatty acid (PUFAs) had a statistically changed ratio in the liver of Tff3 deficient mice: eicosadienoic acid (C20:2)

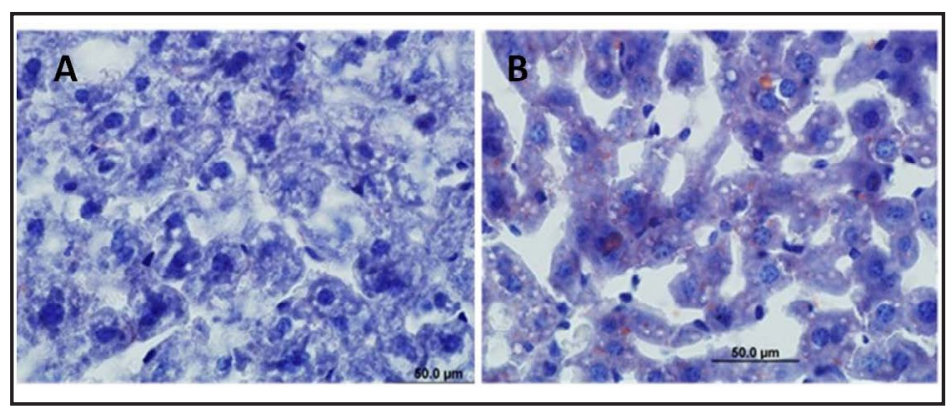

Fig. 2. Oil red staining of neutral lipids in the liver of male WT (A) and Tff3-/- (B) mice

Table 2. Relative percentage of fatty acids as methyl esters (FAME) of FAME in liver homogenate of wild type and Tff 3 -/- mice expressed as $\%$ in total lipid content. RATIO $\omega-3 / \omega-6=($ ALA+DHA+EPA $) /(A A+L N A)$. Data are presented as mean value \pm SEM $(n=7$ per genotype; Student $t$ test). Statistically significant changes are marked as $* \mathrm{p}<0.05,{ }^{* *} \mathrm{p}>0.01$ and ${ }^{* * *} \mathrm{p}<0.001$

\begin{tabular}{|c|c|c|c|}
\hline Fatty acids & $\begin{array}{c}\text { Wild type } \\
\text { [rel \% FAME] }\end{array}$ & $\begin{array}{c}\text { Tff3 -/- } \\
\text { [rel \% FAME] }\end{array}$ & $\begin{array}{c}\text { Fold } \\
\text { change }\end{array}$ \\
\hline \multicolumn{4}{|l|}{ SATURATED } \\
\hline C14:0 myristic acid & $0.34 \pm 0.05$ & $0.21 \pm 0.03^{* * *}$ & $1.6 \downarrow$ \\
\hline C16:0 palmitic acid & $27.92 \pm 2.57$ & $28.06 \pm 0.88$ & \\
\hline C18:0 stearic acid & $8.80 \pm 0.81$ & $13.16 \pm 0.65^{* * *}$ & $1.5 \uparrow$ \\
\hline C 20:0 arachidic acid & $0.28 \pm 0.06$ & $0.42 \pm 0.07^{* *}$ & $1.5 \uparrow$ \\
\hline C 22:0 behenic acid & $0.11 \pm 0.04$ & $0.09 \pm 0.01$ & \\
\hline C 24:0 lignoceric acid & $0.61 \pm 0.13$ & $0.65 \pm 0.09$ & \\
\hline \multicolumn{4}{|l|}{ MONOUNSATURATED } \\
\hline C16:1 palmitoleic acid ( $\omega-9)$ & $3.30 \pm 0.62$ & $1.28 \pm 0.27^{* * *}$ & $2.6 \downarrow$ \\
\hline C18:1 oleic acid ( $\omega-9)$ & $20.10 \pm 2.36$ & $11.22 \pm 1.55^{* * *}$ & $1.8 \downarrow$ \\
\hline C18:1 vaccenic acid $(\omega-7)$ & $2.80 \pm 0.81$ & $1.7 \pm 0.28^{* *}$ & $1.7 \downarrow$ \\
\hline C20:1 eicosenoic (gondoic acid) ( $\omega-9)$ & $0.56 \pm 0.09$ & $0.43 \pm 0.04^{* *}$ & $1.3 \downarrow$ \\
\hline C22:1 erucic acid $(\omega-9)$ & $0.06 \pm 0.02$ & $0.06 \pm 0.01$ & \\
\hline \multicolumn{4}{|l|}{ POLYUNSATURATED } \\
\hline C18:2 (LNA) linoleic acid $(\omega-6)$ & $20.32 \pm 2.78$ & $20.49 \pm 0.98$ & \\
\hline C20:2 eicosadienoic acid $(\omega-6)$ & $0.25 \pm 0.01$ & $0.34 \pm 0.01^{* * *}$ & $1.4 \uparrow$ \\
\hline C20:4 (AA) arachidonic acid $(\omega-6)$ & $6.36 \pm 0.90$ & $9.69 \pm 0.64^{* * *}$ & $1.5 \uparrow$ \\
\hline C18:3 (ALA) alpha linolenic $(\omega-3)$ & $0.63 \pm 0.16$ & $0.42 \pm 0,08^{* *}$ & $1.5 \downarrow$ \\
\hline C20:5 (EPA) eicosapentaenoic $(\omega-3)$ & $0.88 \pm 0.21$ & $0.95 \pm 0.14$ & \\
\hline C22:6 (DHA) docosahexaenoic $(\omega-3)$ & $6.68 \pm 0.48$ & $10.83 \pm 1.77^{* * *}$ & $1.6 \uparrow$ \\
\hline SATURATED FAs & $38.06 \pm 3.33$ & $42.59 \pm 1.67^{* * *}$ & $1.1 \uparrow$ \\
\hline MONOUNSATURATED FAs(MUFAs) & $26.82 \pm 2.60$ & $14.69 \pm 2.00^{* * *}$ & $1.7 \downarrow$ \\
\hline POLYUNSATURATED FAs (PUFAs) & $35.12 \pm 2.60$ & $42.72 \pm 1.30^{* * *}$ & $1.2 \uparrow$ \\
\hline RATIO $\omega-3 / \omega-6$ & $0.30 \pm 0.049$ & $0.40 \pm 0.06^{*}$ & $1.3 \uparrow$ \\
\hline Total & $100 \%$ & $100 \%$ & \\
\hline
\end{tabular}
was increased 1.45-fold, arachidonic acid (AA, C20:4, $\omega$-6) increased 1.4-fold, alpha linolenic acid (ALA, C18:3, $\omega$-3) decreased 1.5-fold and docosahexaenoic acid (DHA, C22:6, $\omega$-3) increased 1.6-fold. Statistically changed PUFAs in sera of Tff3 deficient mice were: linoleic acid (C18:2, $\omega-6)$, which increased 1.3-fold, and alpha linolenic acid (ALA, C18:3, $\omega$-3), the proportion of which was reduced 3-fold.

The amount of total PUFAs was significantly increased (1.2-fold) in the liver of Tff3 -/- mice, while the proportion in the sera was not affected by Tff3 deficiency. Tff3 -/- mice exhibited significant modification of the $\omega-3 / \omega-6$ ratio. Liver $\omega-3 / \omega-6$ ratio was increased (1.3-fold), while the serum ratio was decreased (1.9-fold).

The complex synthesis relationship of monitored FAs is presented (Fig. 4) with marked changes in Tff3 -/- mice compared with wild type (elevated $\uparrow$, decreased $\downarrow$ and no change $\theta$ ). Activity of SCD-1 enzyme was calculated based on the ratio of specific FAs content (C18:1/ C18:0 and C16:1/C16:0), which was reduced 2.7-fold in Tff3 deficient mice compared with WT ones. 
Expression of SIRT1, PPAR $\alpha$, PPARY, PPARS, SOD2, CAT, GPX1 and HNF4 $\alpha$ genes in liver

Expression of several oxidative stress and FA metabolism regulation relevant genes (SIRT1, PPAR $\alpha$, PPAR $\gamma$, PPAR8, SOD2, CAT, GPx1 and HNF4 $\alpha$ ) was monitored in the liver of WT and Tff3 deficient mice (Fig. 5). Tff3 deficient mice exhibit a rather scattered but strong reduction of PPAR $\gamma$ mRNA (it was reduced 7.7-fold compared with WT). Expression of mRNA for SIRT1, PPAR $\alpha$, PPAR $\delta$, SOD2, CAT, GPx1, HNF $4 \alpha$ was not significantly changed by Tff3 deficiency.

SOD2, CAT, GPX1, PPARY, SIRT1 and $P M P 70$ protein expression in liver

Relevant protein expression in liver homogenate of Tff3-/- mice was presented relative to the content in WT mice, which was set as $100 \%$ (Fig. 6). Level of SOD2, CAT, GPx1, PMP70 was not affected by Tff3 deficiency. No activation of inducible NOS (iNOS) was found in any of the genotypes. Tff3-/- mice had a strong reduction of nuclear receptor SIRT1 (reduction to a level equivalent to $25 \%$ of WT level; $\mathrm{p}<0.001$ ) and PPAR $\gamma$ protein level (reduction to $54 \%$ of WT level; $\mathrm{p}=0.003$ ).

Activity of antioxidative enzymes, oxidative stress (TBARS), antioxidative capacity (FRAP) and lipid peroxidation in the liver of WT and Tff3 -/- mice

Activity of liver SOD was not significantly affected in Tff3 -/- (Fig. 7). Tff3 deficient mice had a significantly reduced activity of liver CAT (68 $\%$ of WT activity), while the activity of GPx was significantly increased (158\% of WT activity). Tff3 deficiency had not affected the liver oxidative stress [TBARS (mmol MDA/mg tissue): wt $\left(3.60 \times 10^{-5} \pm 1.38 \times 10^{-5}\right)$ vs Tff3-/- $\left.\left(6.38 \times 10^{-5} \pm 1.77 \times 10^{-5}\right)\right]$, antioxidative capacity [FRAP (mmol Trolox/mg tissue): wt (0.40 \pm 0.01$)$ vs. Tff3-/- $(0.39 \pm 0.02)$ ] and lipid peroxidation [ $\mathrm{LOOH}(\mathrm{mmol} \mathrm{LOOH} / \mathrm{mg}$ total lipids $)$ : wt $\left(1.90 \times 10^{-6} \pm 2.79 \times 10^{-7}\right)$ vs. Tff3-/- $\left.\left(2.25 \times 10^{-6} \pm 3.76 \times 10^{-7}\right)\right]$.

\section{Discussion}

The first function of Tff3 protein was connected with protection of gastrointestinal tract injuries but recent data connect Tff3 protein with metabolically relevant conditions
Table 3. Relative percentage of fatty acids as methyl esters (FAME) in blood serum of wild type and Tff3 -/- mice expressed as \% of FAME in total lipid content. Nd. Means not detected due to low concentration. RATIO $\omega-3 / \omega-6=$ $(\mathrm{ALA}+\mathrm{DHA}+\mathrm{EPA}) /(\mathrm{AA}+\mathrm{LNA})$. Data are presented as mean value \pm SEM ( $n=6$ per genotype, Student t test). Statistically significant changes are marked as $* \mathrm{p} \leq 0.05,{ }^{* *} \mathrm{p} \leq 0.01$ and ${ }^{* * *} \mathrm{p} \leq 0.001$

\begin{tabular}{lccc}
\hline Fatty acids & $\begin{array}{c}\text { Wild type } \\
\text { [rel \% FAME] }\end{array}$ & $\begin{array}{c}\text { Tff3 -/- } \\
\text { [rel \% FAME] }\end{array}$ & $\begin{array}{c}\text { Fold } \\
\text { change }\end{array}$ \\
\hline SATURATED & $1.17 \pm 0.44$ & $1.13 \pm 0.34$ & \\
C14:0 myristic acid & $24.42 \pm 1.42$ & $24.89 \pm 1.69$ & \\
C16:0 palmitic acid & $10.70 \pm 1.51$ & $10.61 \pm 1.01$ & \\
C18:0 stearic acid & $0.26 \pm 0.07$ & $0.46 \pm 0.10^{* * *}$ & $1.8 \uparrow$ \\
C20:0 arachidic acid & $\mathrm{Nd}$ & $\mathrm{Nd}$ & \\
C22:0 behenic acid & $0.48 \pm 0.11$ & $0.41 \pm 0.07$ & \\
C24:0 lignoceric acid & & & \\
MONOUNSATURATED & $2.40 \pm 0.74$ & $1.65 \pm 0.49$ & \\
C16:1 palmitoleic acid $\omega-7$ & $14.89 \pm 2.04$ & $13.71 \pm 0.84$ & \\
C18:1 oleic acid $\omega-9$ & $2.82 \pm 0.42$ & $1.44 \pm 0.28^{* *}$ & $1.5 \downarrow$ \\
C18:1 vaccenic acid $\omega-7$ & $0.46 \pm 0.29$ & $0.89 \pm 0.18^{*}$ & $1.9 \uparrow$ \\
C20:1 eicosenoic (gondoic acid) $\omega-9$ & $\mathrm{Nd}$ & $\mathrm{Nd}$ & \\
C22:1 erucic acid $\omega-9$ & $4.73 \pm 1.10$ & $4.43 \pm 1.01$ & \\
C24:1 nervonic acid $(\omega-9)$ & & & \\
POLYUNSATURATED & $25.98 \pm 3.20$ & $32,01 \pm 1.93^{* *}$ & $1.3 \uparrow$ \\
C18:2 (LNA) linoleic acid $(\omega-6)$ & $0.24 \pm 0.10$ & $0.61 \pm 0.22$ & \\
C20:2 eicosadienoic acid $(\omega-6)$ & $6.23 \pm 1.35$ & $4.64 \pm 1.08$ & \\
C20:4 (AA) arachidonic acid $(\omega-6)$ & $3.13 \pm 1.53$ & $1.02 \pm 0.27 *$ & $3.0 \downarrow$ \\
C18:3 (ALA) alpha linolenic $(\omega-3)$ & $1.30 \pm 0.48$ & $1.40 \pm 0.38$ & \\
C20:5 (EPA) eicosapentaenoic $(\omega-3)$ & $0.46 \pm 0.36$ & $0.55 \pm 0.25$ & \\
C22:6 (DHA) docosahexaenoic $(\omega-3)$ & $0.33 \pm 0.40$ & $0.15 \pm 0.16$ & \\
C20:3 eicosatrienoic acid $(\omega-3)$ & $37.03 \pm 1.24$ & $37.5 \pm 2.13$ & \\
SATURATED FAs & $25.3 \pm 2.59$ & $22.12 \pm 3.69$ & \\
MONOUNSATURATED FAs(MUFAs) & $37.67 \pm 3.81$ & $40.38 \pm 4.18$ & \\
POLYUNSATURATED FAs (PUFAs) & $0.15 \pm 0.04$ & $0.08 \pm 0.02^{* *}$ & $1.9 \downarrow$ \\
RATIO $\omega-3 / \omega-6$ & $100 \%$ & $100 \%$ & \\
Total & & & \\
& & & \\
& & &
\end{tabular}

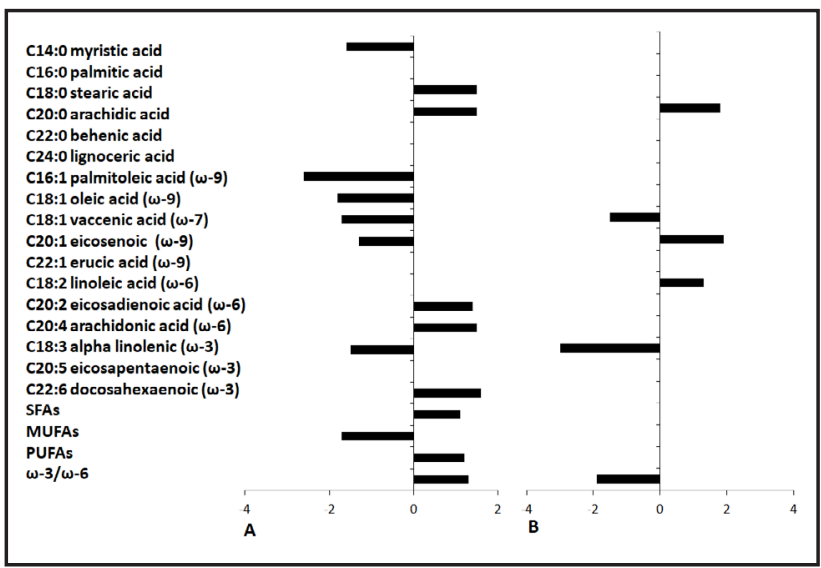

Fig. 3. Fold change of individual fatty acids in liver homogenate (A) and serum (B) between wild type and Tff3 -/- mice. 


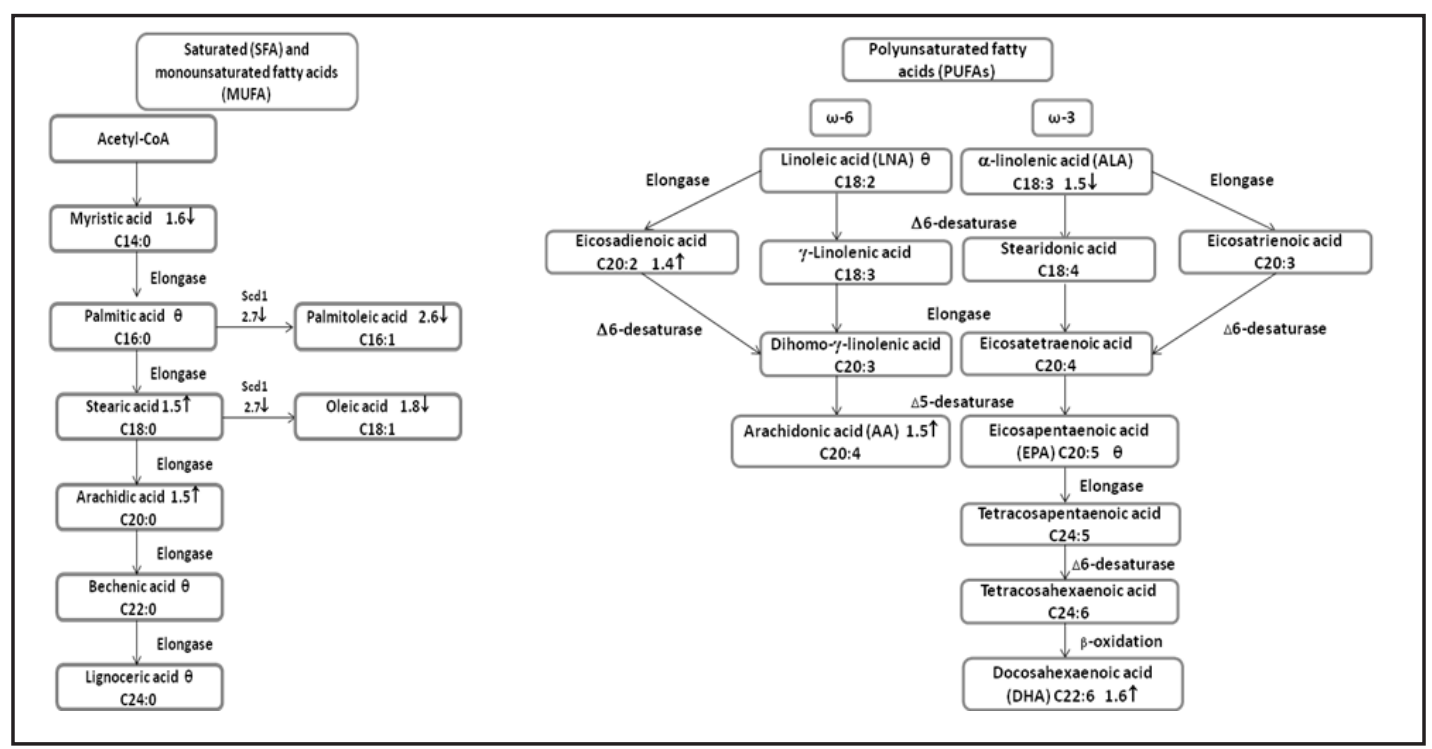

Fig. 4. Fatty acids synthesis in the liver with marked changes (elevated $\uparrow$, decreased $\downarrow$ and no change $\theta$ ) of individual fatty acids in Tff3 -/- mice compared with wild type.

$[8,12]$. The results of the present study showed that Tff3 protein deficiency affects the metabolism of fatty acids in the liver (Fig. $3 \mathrm{~A}$ ) and that Tff3 deficient mice have an increased pool of small lipid vesicles in their hepatocytes (Fig. 2B), with no effect on liver oxidative stress markers (i.e. TBARS, FRAP and $\mathrm{LOOH}$ ) that are often connected with changed liver lipid homeostasis. Due to its wide distribution in the body and presence in blood circulation, we have monitored the overall impact of Tff3 deficiency on health status and metabolic response on glucose/insulin overload.

Tff3 deficiency had no effect on general blood parameters since they were similar to values found in WT mice (Table 1). A statistically relevant change was noticed in the level of total protein concentration, which was reduced by $11 \%$ compared with the level
Fig. 5. Relative expression of CAT, GPX1, SOD2, PPAR $\alpha, \quad$ PPAR $\gamma$, PPAR $\delta, H N F 4 \alpha$ and SIRT1 gene in liver of Tff3 - $\%$ mice $(\mathrm{n}=6) \quad$ compared with wild type mice. Ct values ob-

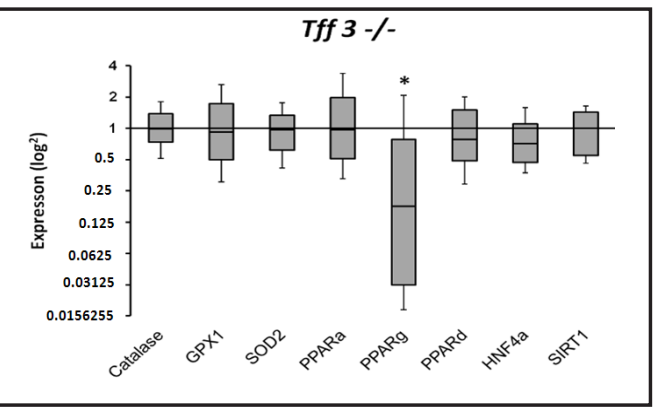
tained by quantitative real time PCR were analyzed with REST 2009. Data are presented relative to WT mice (expression set as 1) as Whisker-box plots in order to see expression median and distribution of permutated expression values with $95 \%$ confidence level.

Fig. 6. Relative protein level of SOD2, CAT, GPx1, PMP70, SIRT1 and PPAR $\gamma$ in liver homogenate of wild type and Tff3 -/- mice. Protein level is presented relative to WT mice as mean \pm SEM of specific

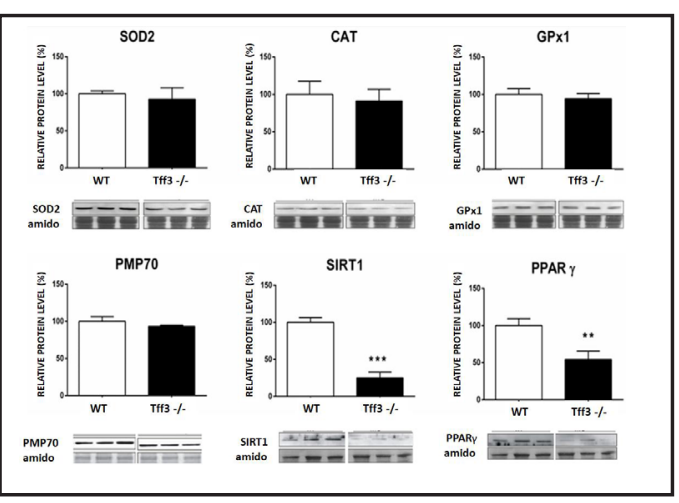
protein band den-

sity normalized with amido black. The differences between groups were compared with by using Student t-test. Statistically significant changes are marked appropriately ${ }^{* *} \mathrm{p} \leq 0.01$ and ${ }^{* * *} \mathrm{p} \leq 0.001$. 


\section{Cellular Physiology Cell Physiol Biochem 2018;47:827-841 \\ \begin{tabular}{l|l} 
DOI: 10.1159/000490039 & $\begin{array}{l}\text { O } 2018 \text { The Author(s). Published by S. Karger AG, Basel } \\
\text { www.karger.com/cpb }\end{array}$
\end{tabular} \\ Bujak et al.: Tff3 $\%$ Genotype Affects Liver Lipid}

found in WT mice. The measurement of total protein level showed changes in two of the most representative proteins, albumin and globulin, which could be caused by reduced liver production or increased loss by urine.

However, GTT and ITT show faster utilization of glucose in Tff3 deficient mice upon glucose or insulin administration (Fig. 1). Direct effect of Tff3 on hepatocytes was demonstrated by overexpression of Tff3 in primary mouse hepatocytes (mice fed by standard diet), which inhibited the expression of gluconeogenic genes and decreased cellular glucose output [11]. This is in line with our observation of miRNA species being used to identify glycolysis/gluoconeogenesis pathways as a possible target of Tff 3 action [34]. Another study by Ge at al., also in the dietinduced obesity mouse model, showed that overexpression of Tff3 in vivo improved glucose

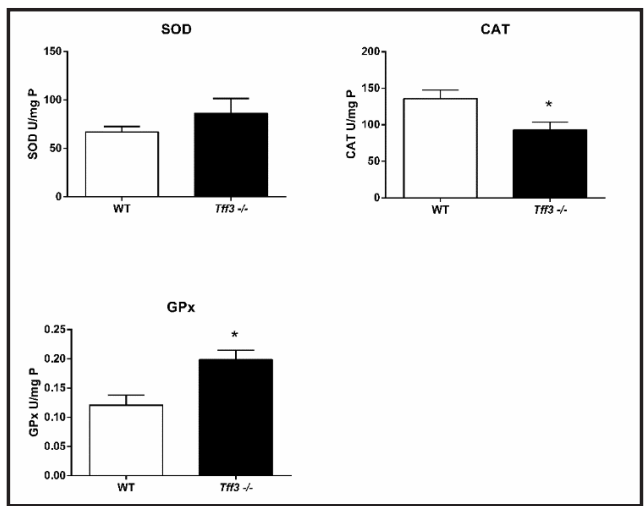

Fig. 7. Activity of antioxidative enzymes in liver homogenate of wild type and Tff3 -/- mice. Enzyme activity ( $\mathrm{U} / \mathrm{mg}$ of protein) is presented as means \pm SEM. The differences between groups were compared by using Student $t$ test and statistically significant changes are marked as $*(\mathrm{p} \leq 0.05)$. tolerance without affecting body weight, fasting insulin, triglyceride, cholesterol and leptin levels [10]. The fact that our Tff3 -/- mice exhibit improved glucose tolerance as well as Tff3 protein overexpressing obese mice models [9] is contradictory at the first moment. This can be explained by different mouse strains (different genetic background) and different diets, contributing to different metabolic and expressional conditions. All of the above contributes to the complexity of this issue and additionally underlines the complexity of metabolic regulation. Nevertheless, reduced expression of liver Tff3 was noticed in different obese mice models of various genetic background (High fat induced obesity, Lepr ${ }^{\mathrm{db}} /$ Lepr $^{\mathrm{db}}$ and Lepr ${ }^{\mathrm{ob}} / \mathrm{Lepr}^{\mathrm{ob}}$ ) [10], early diabetic mice [8] and steatotic liver [12], connecting Tff3 deficiency with conditions caused by specific diseases.

Additionally, liver Tff3 expression was most dramatic (reduction by 600x) in the early diabetes phase of multigene diabesity model called Tally Ho mice [8]. Therefore, we have focused our investigations on the liver. Blood analysis showed that activity of liver enzymes ALT/AST was not affected by Tff3 deficiency, indicating no effect on liver function. Staining of liver sections with H\&E and PAS did not show any differences between Tff3 deficient and WT mice (data not shown). Conversely, Tff3 deficiency caused an increased number of small lipid containing vesicles (Fig. 2B). Besides energy storage, lipid droplets provide reservoirs of structural lipids (such as sterols, fatty acids and phospholipids) used for membrane formation. Given their diverse functions, lipid droplets are situated at the crossroads of membrane biology and energy metabolism as important organelles in maintaining cell homeostasis [35]. Tff3 deficiency did not significantly change the lipid content in the liver, but the content of small lipid vesicles was higher, raising the possibility that Tff3 protein deficiency affects formation of lipid droplets per se. Tff3 is a small protein able to interact with different partners. Lubka et al. identified BAG6 protein as a possible Tff3 interacting partner by using the yeast two-hybrid system [36]. BAG6 complex is a binding factor of tail-anchored (TA) transmembrane proteins and some of them are involved in membrane biogenesis, apoptosis, vesicular trafficking and signal transduction [37]. It is possible that Tff3 protein deficiency affects interaction of BAG6 with TA proteins involved in formation and trafficking of lipid vesicles, resulting in an increased number of small lipid vesicles. Correlating with histological findings (Fig. 2B), total lipids were slightly although not significantly increased in the liver of Tff3 knockout mice. Taking also into account that there was no change in TG level in the sera, we could only confirm increased small lipid vesicle formation with no signs of liver steatosis. 
Fatty acids profile analysis showed that Tff3 deficient mice had a statistically significant different level of numerous fatty acids in the liver and serum compared with WT mice (Fig 3.; Table 2, 3). Thus, the level of SFA $(1.1 \mathrm{x})$ and PUFAs $(1.2 \mathrm{x})$ were increased while the level of MUFAs was decreased $(1.7 \mathrm{x})$ in the liver of Tff3 deficient mice compared with WT ones. In addition, the $\omega-3 / \omega-6$ ratio was elevated in liver $(1.3 x)$ and decreased in serum $(1.9 x)$ of Tff3 deficient mice compared with WT ones. However, total serum levels of cholesterol, TG or HDL did not differ among the groups. Interestingly, content of essential fatty acids that needs to be taken by food is also affected. ALA $(\mathrm{C} 18: 3, \omega-3)$ is reduced in the liver (1.5-fold) and sera (3-fold) while LNA (C18:2, $\omega$-6) is increased 1.3-fold in sera and not affected in the liver. Although the level of specific FAs in the serum was changed, total content of the monitored SFAs, MUFAs and PUFAs was not changed due to Tff3 deficiency, demonstrating no effect on FA utilization and transport. In addition, we also did not observe changes in fatty acid composition in adipose tissue of Tff3 deficient mice (data not shown). All these data indicate that liver is the main site of impaired fatty acid metabolism. Hepatic FAs may derive from endogenous lipogenesis or from the free FA (FFA) plasma pool via active uptake into the hepatocyte. Hepatic lipogenesis includes de novo synthesis of FAs from acetyl-CoA (Fig. 4) or malonyl-CoA that are produced from a number of different pathways within the cell, most commonly carbohydrate catabolism [38]. In mammals, FA synthesis is catalyzed by acetylCoA carboxylase (ACC) and fatty acid synthase (FAS) an enzyme that is complexly regulated by various nuclear receptors (PPARs and the bile acid receptor/farnesoid X receptor [FXR]) [39]. In de novo lipid synthesis pathway (Fig. 4) we have found a decreased amount of myristic (C14:0) fatty acid (1.6 x), suggesting the inhibition of de novo lipidogenesis in the liver of Tff3 deficient mice. Further steps in the synthesis scheme show no differences in palmitic, bechenic and lignoceric acid level. In contrast, the levels of stearic and arachidonic acids were elevated (1.5-fold). Additionally, the ratios of FA, C16:1/C16:0 and C18:1/C18:0, were different in Tff3 deficient mice compared with WT ones. Stearoyl CoA desaturase (SCD1) is a rate-limiting enzyme that catalyzes the biosynthesis of MUFAs from SFAs, mainly palmitoleic (C16:1) and oleic acid (C18:1) from palmitic (C16:0) and stearic acids (C18:0), respectively [40]. Desaturation index (determined by ratios of C18:1/C18:0 or C16:1/C16:0) has been widely used as a marker of SCD1 activity [41], and it was reduced 2.7-fold in Tff3 deficient mice compared with WT ones (Fig. 4). This could be due to lower protein expression or SCD1 activity. There are two possible explanations for this. First, SCD1 gene transcription is regulated by PPAR $\gamma$ and SIRT1 which were found to be downregulated in Tff3 deficient mice (Fig. 6). Second, free PUFAs could bind directly to the transcription factors that are involved in SCD1 expression and inhibit their activity and nuclear abundance [42]. It is important to mention that besides conversion to palmitoleic acid (9cis-16:1) by SCD1, palmitic acid (C16:0) can be converted to another isomer called sapienic acid (6cis-16:1) by fatty acid desaturase 2 (FADS2) enzyme, which is also involved in $\omega-3$ and $\omega-6$ pathway. Sapienic acid detection in human blood and in cancer breast cells demonstrates that it may be synthesized in different tissues and that it plays a significant role in lipid metabolism $[43,44]$. Considering the results of this study, which showed impaired metabolism of MUFA and $\omega-3 / \omega-6$ fatty acids in Tff3-/- mice, it is possible that FADS2 enzyme activity is also changed. However, more detailed and extensive studies will be needed to clarify this assumption.

An intriguing observation in the present study is that Tff 3 deficient mice have elevated levels of PUFAs in the liver, especially AA (C20:4, $\omega-6)$ and DHA (C22:6, $\omega-3)$. Namely, in mammals ALA (C18:3, $\omega-3)$ is converted to eicosapentaenoic acid (EPA, C20:5, $\omega-3)$ in low amounts $(8 \%)$ and -in even lower amounts- to DHA $(\mathrm{C} 22: 6, \omega-3)(<0.1 \%)$. PUFAs are derived from either LNA $(\mathrm{C} 18: 2, \omega-6)$ or ALA $(\mathrm{C} 18: 3, \omega-3)$ by an alternating series of desaturation and elongation reactions depending on the desaturase and elongase activities [45]. The major end products of $\omega-6$ and $\omega-3$ pathways are AA $(C 20: 4, \omega-6)$ and DHA $(C 22: 6, \omega-3)$. DHA is synthesized from ALA in the liver by a series of desaturations, elongations and $\beta$-oxidation (Fig. 4). The desaturations and elongations occur in the ER and the $\beta$-oxidation occurs in the peroxisome, where 24-carbon PUFAs are transferred. When $\beta$-oxidation is affected in the mitochondria, fatty acids are channeled for $\beta$-oxidation in peroxisomes and $\omega$-oxidation

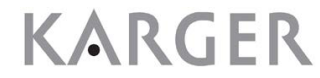




\section{Cellular Physiology Cell Physiol Biochem 2018;47:827-841 \\ \begin{tabular}{l|l} 
and Biochemistry Publishea onlIne: Vlay 28, 2018 & $\begin{array}{l}\text { Co 2018 The Author(s). Published by S. Karger AG, Basel } \\
\text { www.karger.com/cpb }\end{array}$ \\
\hline
\end{tabular} \\ Bujak et al.: Tff3 $\%$ Genotype Affects Liver Lipid}

in microsomes. In relation to this known mechanism, we did not observe any difference in the level of PMP70 protein, taken as a marker for peroxisomal proliferation (Fig. 6). Tff3 -/mice had decreased levels of MUFA and elevated levels of PUFAs in the liver. Oleic acid is the major MUFA found in the membrane and the ratio of SFA to MUFA has been implicated in alteration of membrane fluidity [46]. There is a possibility that decrease of the MUFA content in the liver of Tff3 -/- mice is compensated by elevated levels of PUFAs. This ratio, due to the presence of more double bonds in the fatty acyl chain, could increase in membrane fluidity. Degree of insulin sensitivity and glucose transport is correlated to the amount of PUFAs in the membrane [47]. This might explain why Tff3 -/- mice had increased glucose tolerance and insulin sensitivity compared with WT ones. In addition, Tff3 -/- have decreased $\omega-3 / \omega-6$ ratio in the liver and it is known that a decreased $\omega-3$ deficiency $\omega-6$ ratio is associated with an improvement in whole body glucose tolerance [48].

Tff3 deficiency influenced the synthesis and accumulation of FAs which are not only the source of energy, but also fine modulators of cellular signaling and metabolism [49]. The majority of genes that play key roles in lipid metabolism and their expression are modulated by SIRT1 and nuclear receptors PPARs [50]. SIRT1 is the epigenetic regulator acting as a metabolic sensor affecting expression and activity of various metabolic enzymes and transcription factors such as PPAR $\gamma$, a nuclear receptor central to glucose and lipid homeostasis $[20,23]$. To understand the underlying molecular mechanism(s) responsible for disturbances in fatty acid composition, we studied their genes and protein expression (Fig. 5 and 6). Tff3 deficient mice had a significantly reduced level of SIRT1 (4 fold) compared with WT ones (Fig. 6). Although the level of SIRT1 protein is reduced but not completely abolished in Tff3 deficient mice, they both show increased systemic glucose and insulin sensitivity. In addition, SIRT1 deficient mice also exhibit increased content of hepatic free fatty acid and deregulated fatty acid oxidation genes [51].

Furthermore, the expression of PPAR $\gamma$ was decreased 2-fold in Tff3 deficient mice. Interestingly, the liver specific knockout of PPAR $\gamma$ protected the mice against high fat diet induced obesity and improved their glucose tolerance. In addition, deletion of PPAR $\gamma$ downregulated the genes involved in lipogenesis and $\beta$-oxidation [52]. The reason for such discordant observation in Tff3 deficient mice could be in the existence of small lipid vesicles in contrary to macrovesicular steatosis that was found in the above mentioned work.

Considering that Tff3 knockout mice had an increased level of PUFAs which are susceptible to oxidation, and increased OS is noticed in lipid metabolism in the course of fatty liver development, the markers of OS and the endogenous antioxidant system were examined. The level of TBARS and FRAP in the liver of Tff3 deficient mice showed no difference compared with that found in WT ones, although the activity of some enzymes was changed (Fig. 7). We have detected reduced CAT and increased GPx activity while the protein level of SOD, CAT and GPx1 were not changed in Tff3 deficient mice compared with the levels found in WT ones (Fig. 6). Together, these findings indicate that changes in liver lipid metabolism of Tff3 deficient mice are not connected with oxidative stress and lipid peroxidation.

\section{Conclusion}

In summary, our results demonstrated that systemic Tff3 deficiency affects liver lipid metabolism and accumulation. Increased lipid droplets formation is not accompanied by liver oxidative stress, although expression/activity of monitored enzymes is deregulated compared with that of WT mice. We have revealed altered FAs profile and expression of SIRT1 and PPAR $\gamma$. It is known that Tff3 expression is downregulated by TNF $\alpha$ and IL6, which were originally considered as classical inflammatory cytokines and are now considered to be major links between steatosis, insulin resistance and related inflammatory disorders [53]. Metabolism and maintenance of metabolic homeostasis are extremely complicated processes involving interactions of various organs. Loss of Tff3 gene expression (600- 


\section{Cellular Physiology Cell Physiol Biochem 2018;47:827-841

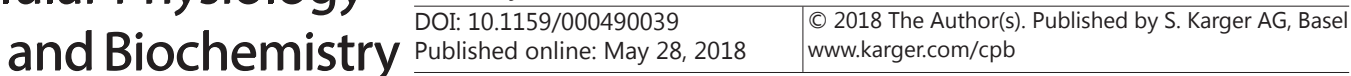 Bujak et al.: Tff3 $\%$ Genotype Affects Liver Lipid}

fold downregulation) in the liver as one of the most prominent events in the early phase of diabetes in diabetic/obese mice its presence in circulation and its regulation by insulin and food intake, suggest Tff3 as; an interesting candidate for further research in metabolic relevant conditions.

\section{Acknowledgements}

All applicable international, national, and/or institutional guidelines for the care and use of animals were followed. Animal housing conditions and animal research protocols are compliant with the ILAR Guide for the Care and Use of Laboratory Animals, Directive on the protection of animals used for scientific purposes (2010/63/EU) and the Croatian Animal Protection Act (OG 135/06, 37/13 and 125/13).

This study was funded by Croatian Science Foundation Grant No. IP-2014-09-6380 (V-ELI Athero), and by Croatian Science Foundation Grant No.: IP-2014-09-4533 (SuMERa).

\section{Disclosure Statement}

The authors declare that they have no conflicts of interests.

\section{References}

1 Thim L: A new family of growth factor-like peptides "Trefoil" disulphide loop structures as a common feature in breast cancer associated peptide (pS2), pancreatic spasmolytic polypeptide (PSP), and frog skin peptides (spasmolysins). FEBS Lett 1989;250:85-90.

-2 Mashimo H, Wu D, Podolsky DK: Impaired Defense of Intestinal Mucosa in Mice Lacking Intestinal Trefoil Factor. Science 1996;274:262-265.

- Vestergaard EM, Poulsen SS, Grønbaek H, Larsen R, Nielsen AM, Ejskjaer K, Clausen JT, Thim L, Nexø E: Development and evaluation of an ELISA for human trefoil factor 3 Clin Chem 2002;48:1689-1695.

4 Madsen J, Nielsen 0, Tornoe I, Thim L, Holmskov U: Tissue localization of human trefoil factors 1, 2, and 3. J Histochem Cytochem 2007;55:505-513.

5 Baus-Loncar M, Giraud AS: Multiple regulatory pathways for trefoil factor (TFF) genes. Cell Mol Life Sci 2005;62:2921-2931.

6 Nozaki I, Lunz JG, Specht S, Park J, Giraud AS, Murase N, Demetris AJ: Regulation and Function of Trefoil Factor Family 3 Expression in the Biliary Tree. Am J Pathol 2004;165:1907-1920.

7 Loncar MB, Al-azzeh E, Sommer P, Marinovic, M Schmehl K, Kruschewski M, Blin N, Stohwasser R, Gott $\mathrm{P}$, Kayademir T: Tumour necrosis factor $\alpha$ and nuclear factor $\kappa \mathrm{B}$ inhibit transcription of human TFF3 encoding a gastrointestinal healing peptide. Inflamm Bowel Dis 2003;52:1297-1303.

8 Brown AC, Olver WI, Donnelly CJ, May ME, Naggert JK, Shaffer DJ, Roopenian DC: Searching QTL by gene expression: analysis of diabesity. BMC Genet 2005;6:12.

9 Jose G, Roa B, Tortolero GS, Gonzalez JE: Trefoil factor 3 (TFF3) expression is regulated by insulin and glucose. J Heal Sci 2013;3:1-12.

10 Ge H, Gardner J, Wu X, Rulifson I, Wang J, Xiong Y, Ye J, Belouski E, Cao P, Tang J, Lee KJ, Coberly S, Wu X, Gupte J, Miao L, Yang L, Nguyen N, Shan B, Yeh WC, Véniant MM, Li Y, Baribault H: Trefoil factor 3 (TFF3) is regulated by food intake, improves glucose tolerance and induces mucinous metaplasia. PLoS ONE 2015;10:e0126924.

11 Xue Y, Shen L, Cui Y, Zhang H, Chen Q Cui A, Fang F, Chang Y: Tff3, as a Novel Peptide, Regulates Hepatic Glucose Metabolism. PLoS ONE 2013;8:e75240.

12 Guillen N, Navarro A, Arnal C, Noone E, Arbone M, Surra C, Muniesa P, Roche HM: Microarray analysis of hepatic gene expression identifies new genes involved in steatotic liver. Physiol Genomics 2009;37:187198. 


\section{Cellular Physiology Cell Physiol Biochem 2018;47:827-841 \begin{tabular}{ll|l} 
and Biochemistry & $\begin{array}{l}\text { DOI: 10.1159/000490039 } \\
\text { Published onIIne: VIay 28, } 2018\end{array}$ & $\begin{array}{l}\text { C } 2018 \text { The Author(s). Published by S. Karger AG, Basel } \\
\text { www.karger.com/cpb }\end{array}$ \\
\hline
\end{tabular}}

Bujak et al.: Tff3 $\%$ Genotype Affects Liver Lipid

13 Taub R: Liver regeneration: from myth to mechanism. Nat Rev Mol Cell Biol 2004;5:836-847.

14 Nguyen P, Leray V, Diez M, Serisier S, Le Bloc HJ, Siliart B, Dumon H: Liver lipid metabolism. J Anim Physiol Anim Nutr (Berl) 2008;92:272-283.

15 Rui L: Energy metabolism in the liver. Compr Physiol 2014;4:177-197.

16 Liu J, Han L, Zhu L, Yu Y: Free fatty acids, not triglycerides, are associated with non-alcoholic liver injury progression in high fat diet induced obese rats. Lipids Health Dis 2016;15:27.

17 Wang D, Wei Y, Pagliassotti MJ: Saturated fatty acids promote endoplasmic reticulum stress and liver injury in rats with hepatic steatosis. Endocrinology 2006;147:943-951.

18 Rolo AP, Palmeira CM: Diabetes and mitochondrial function: Role of hyperglycemia and oxidative stress. Toxicol Appl Pharmacol 2006;212:167-178.

19 Balcer-Kubiczek EK, Harrison GH, Xu JF, Gutierrez PL: Coordinate late expression of trefoil peptide genes (pS2/TFF1 and ITF/TFF3) in human breast, colon, and gastric tumor cells exposed to X-rays. Mol Cancer Ther 2002;1:405-15.

20 Schug TT, Li X: Sirtuin 1 in lipid metabolism and obesity. Ann Med 2011;43:198-211.

21 Nassir F, Ibdah JA: Sirtuins and nonalcoholic fatty liver disease. World J Gastroenterol 2016;22:1008410092.

22 Poulsen L la C, Siersbæk M, Mandrup S: PPARs: Fatty acid sensors controlling metabolism. Semin Cell Dev Biol 2012;23:631-639.

-23 Schadinger SE, Bucher NLR, Schreiber BM, Farmer SR: PPARgamma2 regulates lipogenesis and lipid accumulation in steatotic hepatocytes. Am J Physiol Endocrinol Metab 2005;288:E1195-205.

-24 Bligh E, Dyer W: A rapid method of total lipid extraction and purification. Can J Biochem Physiol 1959;37:911-917.

-25 Zambonin L, Ferreri C, Cabrini L, Prata C, Chatgilialoglu C, Landi L: Occurrence of trans fatty acids in rats fed a trans-free diet: a free radical-mediated formation? Free Radic Biol Med 2006;40:1549-1556.

-26 Pfaffl MW, Horgan GW, Dempfle L: Relative expression software tool (REST) for group-wise comparison and statistical analysis of relative expression results in real-time PCR. Nucleic Acids Res 2000;30:e36.

27 Sobočanec S, Filić V, Matovina M, Majhen D, Šafranko ŽM, Hadžija MP, Krsnik Ž, Kurilj AG, Šarić A, Abramić M, Balog T: Prominent role of exopeptidase DPP III in estrogen-mediated protection against hyperoxia in vivo. Redox Biol 2016;8:149-159.

28 Vuković R, Blažetić S, Oršolić I, Heffer M, Vari SG, Gajdoš M, Krivošíková Z, Kramárová P, Kebis A, Has-Schön E: Impact of ovariectomy, high fat diet, and lifestyle modifications on oxidative/antioxidative status in the rat liver. Croat Med J 2014;55:218-227.

29 Cosic A, Jukic I, Stupin A, Mihalj M, Mihaljevic Z, Novak S, Vukovic R, Drenjancevic I: Attenuated flowinduced dilation of middle cerebral arteries is related to increased vascular oxidative stress in rats on a short-term high salt diet. J Physiol 2016;594:4917-4931.

-30 Oakes KD, Van Der Kraak GJ: Utility of the TBARS assay in detecting oxidative stress in white sucker (Catostomus commersoni) populations exposed to pulp mill effluent. Aquat Toxicol 2003;63:447-463.

-31 Benzie I, Strain J: The ferric reducing ability of plasma (FRAP) as a measure of "antioxidant power": the FRAP assay. Anal Biochem 1996;239:70-76.

32 Kramer SD, Hurley J a, Abbott NJ, Begley DJ: Lipids in blood-brain barrier models in vitro I: Thin-layer chromatography and high-performance liquid chromatography for the analysis of lipid classes and longchain polyunsaturated fatty acids. In vitro Cell Dev Biol Anim 2002;38:557-565.

-33 Mihaljević B, Katušin-Ražem B, Ražem D: The reevaluation of the ferric thiocyanate assay for lipid hydroperoxides with special considerations of the mechanistic aspects of the response. Free Radic Biol Med 1996;21:53-63.

34 Shah AA, Leidinger P, Keller A, Wendschlag A, Backes C, Baus-Loncar M, Meese E, Blin N: The intestinal factor Tff3 and a miRNA network regulate murine caloric metabolism. RNA Biol 2011;8:77-81.

35 Thiam AR, Farese RJ, Walther TC: The Biophysics and Cell Biology of Lipid Droplets. Nat Rev Mol Cell Biol 2013;14:775-786.

-36 Lubka M, Shah AA, Blin N, Baus-Loncar M: The intestinal trefoil factor (Tff3), also expressed in the inner ear, interacts with peptides contributing to apoptosis. J Appl Genet 2009;50:167-171.

-37 Leznicki P, Clancy A, Schwappach B, and High S: Bat3 promotes the membrane integration of tail-anchored proteins. J Cell Sci 2010;123:2170-2178. 


\section{Cellular Physiology Cell Physiol Biochem 2018;47:827-841

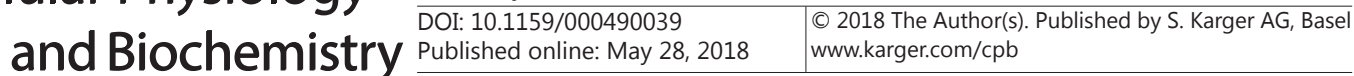 \\ Bujak et al.: Tff3 $\%$ Genotype Affects Liver Lipid}

-38 Sanders FWB, Griffin JL: De novo lipogenesis in the liver in health and disease: More than just a shunting yard for glucose. Biol Rev 2016;91:452-468.

-39 Bechmann LP, Hannivoort RA, Gerken G, Hotamisligil GS, Trauner M, Canbay A: The interaction of hepatic lipid and glucose metabolism in liver diseases. J Hepatol 2012;56:952-964.

40 Ntambi JM, Miyazaki M: Regulation of stearoyl-CoA desaturases and role in metabolism. Prog Lipid Res 2004;43:91-104.

41 Flowers MT: The delta9 fatty acid desaturation index as a predictor of metabolic disease. Clin Chem 2009;55:2071-2073.

-42 Xu J, Teran-Garcia M, Park JHY, Nakamura MT, Clarke SD: Polyunsaturated Fatty Acids Suppress Hepatic Sterol Regulatory Element-binding Protein-1 Expression by Accelerating Transcript Decay. J Biol Chem 2001;276:9800-9807.

43 Sansone A, Tolika E, Louka M, Sunda V, Deplano S, Melchiorre M, Anagnostopoulos D, Chatgilialoglu C, Formisano C, Di Micco R, Faraone Mennella MR, Ferreri C: Hexadecenoic Fatty Acid Isomers in Human Blood Lipids and Their Relevance for the Interpretation of Lipidomic Profiles. PLoS ONE 2016; 5;11:e0152378.

44 Park HG, Kothapalli KSD, Park WJ, DeAllie C, Liu L, Liang A, Lawrence A, Brenna JT: Palmitic acid (16:0) competes with omega-6 linoleic and omega-3 $\alpha$-linolenic acids for FADS2 mediated $\Delta 6$-desaturation. Biochim Biophys Acta 2016;1861:91-97.

-45 Parker-Barnes JM, Das T, Bobik E, Leonard AE, Thurmond JM, Chaung LT, Huang YS, Mukerji P: Identification and characterization of an enzyme involved in the elongation of n- 6 and n-3 polyunsaturated fatty acids. Proc Natl Acad Sci U S A 2000;97:8284-8289.

46 Pan DA, Hulbert AJ, Storlien LH: Dietary fats, membrane phospholipids and obesity. J Nutr 1994;124:15551565.

-47 Pan DA, Lillioja S, Milner MR, Kriketos AD, Baur LA, Bogardus C, Storlien LH: Skeletal muscle membrane lipid composition is related to adiposity and insulin action. J Clin Invest 1995;96:2802-2808.

48 Smith BK, Holloway GP, Reza-Lopez S, Jeram SM, Kang JX, Ma DWL: A decreased n-6/n-3 ratio in the fat-1 mouse is associated with improved glucose tolerance. Appl Physiol Nutr Metab 2010;35:699-706.

49 Kremmyda L-S, Tvrzicka E, Stankova B, Zak A: Fatty acids as biocompounds: their role in human metabolism, health and disease - a review. part 2: fatty acid physiological roles and applications in human health and disease. Biomed Pap Med Fac Univ Palacky Olomouc Czech Repub 2011;155:195-218.

50 Guarente L: Sirtuins as potential targets for metabolic syndrome. Nature 2006;444:868-874.

51 Rodgers JT, Puigserver P: Fasting-dependent glucose and lipid metabolic response through hepatic sirtuin 1 Proc Natl Acad Sci 2007;104:12861-12866.

52 Matsusue K, Haluzik M, Lambert G, Yim SH, Gavrilova O, Ward JM, Brewer B, Reitman ML, Gonzalez FJ: Liver-specific disruption of PPAR $\gamma$ in leptin-deficient mice improves fatty liver but aggravates diabetic phenotypes. J Clin Invest 2003;111:737-747.

53 Meli R, Raso GM, Calignano A: Role of innate immune response in non-alcoholic fatty liver disease: Metabolic complications and therapeutic tools. Front Immunol 2014;5:1-15. 